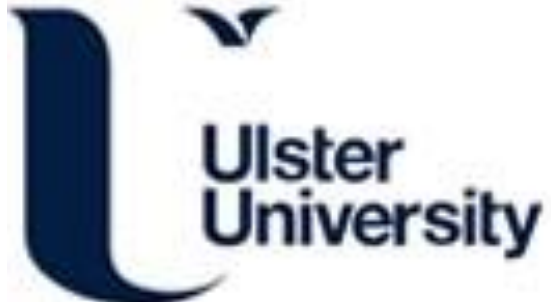

\section{Cycles, Vocabulary Items and stem forms in Hiaki}

Harley, H., \& Tubino Blanco, M. (2013). Cycles, Vocabulary Items and stem forms in Hiaki. In O. Matushansky, \& A. Marantz (Eds.), Distributed Morphology Today: Morphemes for Morris Halle (pp. 117-134). MIT Press. http://mitpress.mit.edu/books/distributed-morphology-today

Link to publication record in Ulster University Research Portal

Published in:

Distributed Morphology Today: Morphemes for Morris Halle

Publication Status:

Published (in print/issue): 19/07/2013

\section{Document Version}

Author Accepted version

\section{General rights}

Copyright for the publications made accessible via Ulster University's Research Portal is retained by the author(s) and / or other copyright owners and it is a condition of accessing these publications that users recognise and abide by the legal requirements associated with these rights.

\section{Take down policy}

The Research Portal is Ulster University's institutional repository that provides access to Ulster's research outputs. Every effort has been made to ensure that content in the Research Portal does not infringe any person's rights, or applicable UK laws. If you discover content in the Research Portal that you believe breaches copyright or violates any law, please contact pure-support@ulster.ac.uk. 


\title{
CYCLES, VOCABULARY ITEMS AND STEM FORMS IN HIAKI
}

\author{
HeIDI HARLEY \\ MERCEDES TUBino BLANCO \\ University of Arizona and University of Seville
}

\section{Introduction}

The analysis of arbitrary morphological classes has a number of architectural implications in Distributed Morphology (Halle and Marantz 1993). There is no central repository of Saussurean 'words' in the framework-no sound-meaning pairings that are the building blocks for both phonological and semantic sentence-level representations. Instead, there are separate lists. One list contains all syntactic and semantic information necessary for the derivation of a well-formed LF representation, and forms the input to the syntactic derivation. A second list, the Vocabulary, describes the phonological realizations that are inserted as exponents of particular syntactic terminal nodes, following all syntactic operations. This raises the question of where class features are located. What elements do rules which are sensitive to class membership refer to? Are they sensitive to properties of the abstract syntacticosemantic formatives of the first list? 
Or are they instead sensitive to properties of the phonological exponents, the Vocabulary Items in the second list?

In Distributed Morphology, any features which are syntactically (and possibly semantically) active must be a property of the abstract morphemes which are input to syntactic derivation. Embick and Halle (2005) treat even Latin conjugation class features in this fashion, attaching them to the roots in the first list, input to the syntax.

In contrast, we will argue that class features in Hiaki are not properties of roots in the syntax but rather are properties of Vocabulary Items, the phonological exponents inserted at the end of the syntactic derivation. Irregular morphophonological rules (Readjustment Rules) apply to a particular class of Vocabulary Items in the appropriate morphosyntactic environment. Classifications of this kind play no role in the syntactic/semantic computation, but are crucial in triggering the application of the appropriate morphophonological rule to yield the correct surface form in such cases. The existence of such morphophonological classifications, irrelevant to syntax, is thus an argument against the lexeme, as such, and in favor of the DM-style separation of the two lists: List 1, input to the syntax (the source of the Numeration in Minimalist syntactic theories), and List 2, Vocabulary Items which simply realize the output of the syntax. Further, the Hiaki case provides a clear argument for Vocabulary Insertion applying to Root elements (lmorphemes, in Harley \& Noyer 2000's terminology), as well as to f-morphemes. In addition, the notion of a phasal cycle within the word proves useful in permitting a simple statement of the relevant conditioning context for the application of morphophonological rules.

The Hiaki case presents many of the same morals for the architecture and the notion of 'stem' as the Latin perfect does, as elucidated in Embick and Halle (2005), but some of the issues 
arise in even starker relief due to the cross-categorial nature of the stem classes, and especially due to the interaction of the stem classes with suppletion, in particular with the suppletive roots of Hiaki.

\section{Hiaki stem classes}

In Hiaki (Yaqui), lexical stems have bound and free alternants. The bound forms are used as the base for affixation of (broadly speaking) derivational morphology, while the free forms are the base for affixation of (broadly speaking) inflectional morphology, and also of course can also stand alone, without any affix. The bound and free stems for poona, 'play, beat' and kiima, 'bring(pl.obj)', are illustrated in (1), the latter affixed with a derivational suffix. ${ }^{1}$

(1)
Free
Bound
a. poona
pon-tua
play
play-caus
'is playing'
'is making (someone) play'
b. kiima
kima'a-tua
bring.pl
bring.pl-caus
'is bringing (things)'
'is making (someone) bring (things)'

An almost-complete list of the free-stem-selecting and bound-stem-selecting suffixes are listed below in (2)a and b respectively:

1 Gloss key: APPL: applicative; CAUS: causative; CESS: cessative; COMPL: completive; DESID: desiderative; DIR: directive; IMPF: imperfective; INCH: inchoative; ICAUS: indirect causative; INTR: intransitive; IRR: irrealis; OBJ: object; QUOT: quotative; PST: past; PASS: passive; PERF: perfective; PL: plural; PPL: past participle; PROSP: prospective; REL: relative; SG: singular; SUBJ: subject; TR: transitive 
(2) Bound-stem and free-stem suffixes of Hiaki (Harley and Tubino Blanco2010)

a) Hiaki verbal suffixes that require the bound stem (in no particular order)

$\begin{array}{llllll}\text {-tua (caus) } & \text {-'ea (desid) } & \text {-su (compl) } & \text {-se/-vo (go) } & \text {-pea (desid) } & \text {-yaate (cess) } \\ \text {-tevo (icaus) } & \text {-ri (obj.ppl) } & \text {-la (ppl) } & \text {-taite (inch) } & \text {-'ii’aa (desid) } & \text {-siime (go along) } \\ \text {-ria (appl) } & \text {-tu (become) } & \text {-ri (ppl) } & \text {-naate (inch) } & \text {-hapte (inch) } & \text {-sae (dir) } \\ \text {-roka (quot) } & \text {-vae (prosp) } & \text {-le (consider) } & \text {-wa (pass) } & \text {-ne (irr) } & \text {-na (pass.irr) }\end{array}$

b) Hiaki verbal suffixes that require the free stem (again in no particular order) -k (perf) -ka (ppl) -n (p.impf) -kan (pst.impf) $\quad$-o (if/when) $\quad$-‘u (obj.rel) $\quad$ me (subj.rel) Note that a single word can (and often does) contain both derivational and inflectional suffixes; in such cases, the derivational suffixes occur closer to the stem than the inflectional one (as expected) and the bound stem form is chosen, as in, for example, the perfective form of the causative of (1a) above, pon-tua- $k$, 'play-caus-perf', i.e. 'made (someone) play'. ${ }^{2}$

While it is the case that several of the free-stem suffixes are simple coda consonants, others are CV or CVC syllables; many of the bound-stem suffixes are also CV syllables, so it seems unlikely that the choice of bound or free stem is driven by prosodic requirements. In addition to the suffixes listed in (2)b, the bound stem form is also required for the non-head member of any compound (verbal or nominal); see section 3.2 below for exemplification and discussion.

Harley and Tubino Blanco 2010 describe the various patterns of bound stem formation in verbs, distinguishing three primary stem classes and several sub-classes and irregularities.

$2 \quad$ It is also worth noting that derivational suffixes can iterate, and that many of them have bound-stem forms as well (analogous to what Bermúdez-Ortero 2013 calls 'suffix stumps' in Spanish). For example, the suffix taite, 'start', has a bound stem form -taiti-, which occurs when another suffix from the list in (2a) follows it. 
Classes are distinguished according to the shape of the bound stem and the nature of its relationship to the free stem. We summarize these below.

The three primary classes, comprising dozens of exemplars each, are distinguished by whether the stem form is a truncated version of the free form (Class 1), an augmented version containing an extra syllable of the form $-2 V$, where the vowel is a copy of the final vowel of the stem (Class 2), or identical to the free form (Class 3). Each type is exemplified in Table 1:

Table 1 Major Stem Alternation Classes of Hiaki

\begin{tabular}{|c|c|c|c|c|c|c|c|c|}
\hline \multicolumn{3}{|c|}{ Class 1: Truncation } & \multicolumn{3}{|c|}{ Class 2: Echo-vowel } & \multicolumn{3}{|c|}{ Class 3: Invariant } \\
\hline free & bound & Engl & free & bound & Engl & free & bound & Engl \\
\hline $\begin{array}{l}\text { a. poona } \\
\text { b. miika } \\
\text { c. bwase }\end{array}$ & $\begin{array}{l}\text { pon- } \\
\text { mik- } \\
\text { bwas- }\end{array}$ & $\begin{array}{l}\text { 'pound' } \\
\text { 'give’ } \\
\text { 'cook(intr.) }\end{array}$ & $\begin{array}{l}\text { a. bwasa } \\
\text { b. kiima } \\
\text { c. yoore }\end{array}$ & $\begin{array}{l}\text { bwasa'a- } \\
\text { kima'a- } \\
\text { yore'e- }\end{array}$ & $\begin{array}{l}\text { 'cook (tr)' } \\
\text { 'bring(pl)' } \\
\text { 'heal' }\end{array}$ & $\begin{array}{l}\text { a. kivacha } \\
\text { b. hamta } \\
\text { c. suua }\end{array}$ & $\begin{array}{l}\text { kivacha- } \\
\text { hamta- } \\
\text { sua- }\end{array}$ & $\begin{array}{l}\text { 'bring(sg) } \\
\text { 'break' } \\
\text { 'care.for' }\end{array}$ \\
\hline
\end{tabular}

It is important to note that vowel shortening in the stem forms is a regular process in the language, which usually occurs quite generally, under any kind of affixation, to free as well as bound stems. A change from long to short vowel between free and bound forms, then, is not part of the stem-formation process, but rather a regular phonological rule of the language triggered by any kind of affixation.

There are several minor subclasses of stems. Three of these minor classes are listed in Table 2:

Table 2: Minor stem alternation subclasses

\begin{tabular}{|c|c|c|c|c|c|c|c|c|}
\hline \multicolumn{3}{|c|}{ Subclass i: $-e \rightarrow-i$} & \multicolumn{3}{|c|}{ Subclass ii: $e^{\prime} e \rightarrow-i{ }^{\prime} i-$} & \multicolumn{3}{|c|}{ Subclass iii: $-u \rightarrow-o e$} \\
\hline free & bound & Engl & free & bound & Engl & free & bound & Engl \\
\hline $\begin{array}{l}\text { a. hamte } \\
\text { b. chihakte }\end{array}$ & $\begin{array}{l}\text { hamti- } \\
\text { chihakti }\end{array}$ & $\begin{array}{l}\text { 'break(intr.) } \\
\text { 'smash' }\end{array}$ & $\begin{array}{l}\text { a. he'e } \\
\text { b. ne'e }\end{array}$ & $\begin{array}{l}\text { hi'i- } \\
\text { ni'i- }\end{array}$ & $\begin{array}{l}\text { 'drink' } \\
\text { 'fly' }\end{array}$ & $\begin{array}{l}\text { a. kiimu } \\
\text { b. vaasu }\end{array}$ & $\begin{array}{l}\text { kimoe- } \\
\text { vasoe- }\end{array}$ & $\begin{array}{l}\text { 'bring(sg)' } \\
\text { 'soak' }\end{array}$ \\
\hline $\begin{array}{l}\text { c. yu'e } \\
\text { d. vuite }\end{array}$ & $\begin{array}{l}\text { yu'i- } \\
\text { vuiti- }\end{array}$ & $\begin{array}{l}\text { ‘undo’ } \\
\text { 'run(sg)' }\end{array}$ & $\begin{array}{l}\text { c. ye'e } \\
\text { d. che'e }\end{array}$ & $\begin{array}{l}\text { yi'i- } \\
\text { chi'i }\end{array}$ & $\begin{array}{l}\text { 'dance' } \\
\text { 'suckle' }\end{array}$ & & & \\
\hline
\end{tabular}


Another group of subclasses contains free forms which end in two distinct vowels (usually separated by a glottal stop, but sometimes not, or optionally so). Their corresponding bound stem is created by changing the second of the two vowels to match the first; a glottal may appear in the bound form even if it is absent in the free form:

Table 3: Vowel-copying subclasses

\begin{tabular}{|c|c|c|c|c|c|}
\hline \multicolumn{3}{|c|}{ Subclass iv: - o'a/-oa $\rightarrow$-o’o-/-oo- } & \multicolumn{3}{|c|}{ Subclass v: $-e^{\prime} a \rightarrow-e^{\prime} e-$} \\
\hline free & bound & Engl & free & bound & Engl \\
\hline $\begin{array}{l}\text { a. hi'ivoa } \\
\text { b. hovoa } \\
\text { c. ko'a }\end{array}$ & $\begin{array}{l}\text { hi'ivoo- } \\
\text { hovo'o- } \\
\text { ko'o- }\end{array}$ & $\begin{array}{l}\text { ‘cook’ } \\
\text { 'get full’ } \\
\text { 'chew’ }\end{array}$ & $\begin{array}{l}\text { a. eo'ote'a } \\
\text { b. ea } \\
\text { c. me'a }\end{array}$ & $\begin{array}{l}\text { eo'ote'e- } \\
\text { ee- } \\
\text { me'e- }\end{array}$ & $\begin{array}{l}\text { 'be nauseated' } \\
\text { 'feel' } \\
\text { 'kill(sg)' }\end{array}$ \\
\hline d. to' $a$ & to'o- & 'pour, lay down(pl)' & & & \\
\hline \multicolumn{3}{|c|}{ Subclass vi: $-a^{\prime} e \rightarrow-a^{\prime} a-$} & \multicolumn{3}{|c|}{ Subclass vii: $-u^{\prime} e /-u^{\prime} a \rightarrow-u^{\prime} u-$} \\
\hline free & bound & Engl & free & bound & Engl \\
\hline a. bwa'e & $b w a a^{\prime}$ & 'eat' & \multirow{2}{*}{$\begin{array}{l}\text { a. nu'e } \\
\text { b. yu'a }\end{array}$} & \multirow{2}{*}{$\begin{array}{l}n u^{\prime} u- \\
\text { yu'u- }\end{array}$} & \multirow{2}{*}{$\begin{array}{l}\text { 'get, acquire' } \\
\text { 'push' }\end{array}$} \\
\hline & & & & & \\
\hline
\end{tabular}

In addition to these groups of forms, there are a number of effectively irregular forms, whose bound stems are not related to their free forms according to any of the patterns exemplified in the tables above, or to any other pair that we know of. A sampling of these unique cases is given in (3).

(3) Irregular free bound pairs:
a. yepsa $\rightarrow$ yevih- 'arrive (sg)'
b. suulu $\rightarrow$ suluu- 'slide, slip'
c. sevea $\rightarrow$ seve- 'catch a cold, get cold'
d. suawa $\rightarrow$ suan- 'be watched'
e. kepe $\rightarrow$ kup- 'close one's eyes'
f. hia $\rightarrow$ hiu- 'vocalize'
g. ho'otia $\rightarrow$ ho'otiu- 'snore'
h. ve'a $\rightarrow$ vi'i- 'save, reserve'

An important fact to note about all the bound stem forms, of whatever class, is that they are phonologically related to their free forms. Consonantal material is not affected by the 
alternation, with one or two types of exceptions (the general $s \rightarrow h$ / _ $~ C ~ p a t t e r n$, and the restricted $v \rightarrow p$ and $c h \rightarrow t$ alternations). Similarly, the vowel in the first syllable of the stem is not affected by the free/bound alternation, the only exceptions being the $e \rightarrow i$ alternations in subclass (ii) and (3)h, and the irregular kepe $\rightarrow$ kup- pair in (3)e. To the best of our knowledge, there are no suppletive bound-stem forms in the language-there is no case in which the bound form is phonologically unrelated to the free form. (There is considerable suppletion in the language, as discussed in section 4 below, but it is never conditioned by the bound-stem/freestem alternation.)

Below, following Embick and Halle (2005), we will build an argument from these Hiaki facts against the listing of stem forms in Hiaki. Rather, we will argue that the bound stem forms should be derived via the application of Readjustment Rules—-phonological rules restricted to apply to only a given group of vocabulary items, which apply following vocabulary insertionrather than by competition for exponence of a given Root node.

\section{Listedness vs. Readjustment: Stems in Distributed Morphology}

We now turn to a discussion of the theoretical implications of the Hiaki free and bound stem forms. First we review the conclusions of Embick and Halle (2005) concerning the superflous nature of the notion of 'stem' in Distributed Morphology. We then present two arguments against the notion of listing of stem forms in Hiaki, along the lines of the argumentation Embick and Halle (2005) present against the proposal of Aronoff (1994) concerning the listing of Latin verb stem forms. 


\subsection{On the non-listedness of stems in DM: Embick and Halle (2005)}

Embick and Halle (2005) provide an extended discussion of the status of the notion 'stem' in Distributed Morphology. In particular, they reprise the argument against the position of Anderson (1992) according to which different but phonologically-related stem forms such as sing sang are listed, competing with each other for exponence in the same way that distinct, listed suppletive/allomorphic forms such as go went or -ed/-t do. ${ }^{3}$ Their conclusion, echoing the discussion of Marantz (1997) and Halle and Marantz (1993) is that such alternations are substantially different from suppletive cases, the latter being truly rare within and across languages. If the sing sang alternation is treated via listing and competition, exactly as suppletion is treated, the theory itself imposes no principled distinction between suppletion and restricted but basically phonological alternations; the result is simply a cline from maximal irregularity to complete irregularity. In contrast, if the vowel change in sing sang is implemented by a morphophonological Readjustment Rule, it is expected that such alternations should behave in accordance with normal phonological patterns, which, by and large, they do.

Halle and Embick propose a treatment of Latin verb formation in response to a stemstorage model proposed by Aronoff (1994). In their account, a particular set of readjustment rules are triggered in the environment of a certain exponent of the Asp node, thus explaining the appearance of a selectional relationship between a particular stem form and those aspect exponents. A truly selectional effect would require the listing of the stem form (so it could be selected for), but given the independent necessity of readjustment rules, the fact that the same

$3 \quad$ Siddiqi (2009) proposes an approach which brings a stem-listing analysis of English irregularity into a Distributed Morphology model; the remarks of Embick and Halle (2005), and the arguments advanced here, also pose a challenge to such versions of DM. 
effect can be captured via a restriction on a readjustment rule means that the positing of a listed stem form to account for these cases is unmotivated.

We can easily imagine how a 'listing' account of Hiaki verb stem forms would work. The free form of a given Hiaki verb and its bound form would each be listed as alternate phonological forms for a single lexeme (or element from List 1, in DM terms). One would be the 'elsewhere' form, inserted when no more specific criterion is met. Although it might seem natural to assume that the free form is the 'elsewhere' form, in fact it is easier to specify a unified environment for occurrences of free Hiaki verb stems than for bound ones: basically, the free form occurs whenever the verb is inflected, which we could characterize as 'whenever $\mathrm{V}$ is immediately adjacent to $\mathrm{Asp}^{0}{ }^{0}$ (which might, of course, have a null realization, as in the present tense, producing the un-affixed free forms). The bound stem, then, would be the elsewhere form, occurring any time the verb was not adjacent to $\mathrm{Asp}^{0}$, which in fact will be exactly the set of environments in which it is affixed with derivational morphology. To illustrate how such a 'listing' analysis would play out, vocabulary insertion rules of this kind given below for poona 'play.instrument' (Truncation class), bwasa 'cook' (Echo vowel class) and chihakte 'smash' (e $\rightarrow \mathrm{i}$ class), as well as the unique bound stem of hia 'sound, vocalize' are given below. An 'invariant' class item like sova 'roast' would only have one listed form:
a. $\quad[\mathrm{PON}]_{\mathrm{V}} \rightarrow$ 'play.instrument, strike'
poona /
pon Elsewhere
b. $\quad\left[\right.$ BWASA'A $_{\mathrm{V}} \rightarrow$ 'cook'
bwasa / Asp $^{0}$
c. $\quad[\mathrm{CHIHAKTI}]_{\mathrm{V}} \rightarrow$ 'smash'
chihakte / chihakti Elsewhere




$\begin{array}{llll}\text { d. } \quad \begin{array}{l}\text { hia } \\ \text { 'sound }\end{array} & \rightarrow & \text { hiu }{ }_{\mathrm{V}} \text { Asp }^{0} \\ \text { elsewhere }\end{array}$

We will see that such an account suffers two significant drawbacks, described in the next section.

\subsection{The non-listedness of Hiaki stem forms: Two problems}

The 'listing' account of Hiaki stem alternations described above suffers from two substantial problems, the first of which is no doubt immediately obvious to the reader. The first problem is lack of insight into the morphophonology of Hiaki, the 'arbitrariness' issue discussed by Embick and Halle (2005). Listed forms need not bear any relationship to their other alternant or to each other. There is no reason why they should fall into the general classes described in section 2 above, which are characterizable in broadly phonological terms ('truncation', 'echo vowel', etc.). Suppletive stem alternants should be possible, but do not occur. Positing stem classes is motivated by such groups of forms, but the listing approach does not reflect such groupings. In fact, the notion of 'class' drops away entirely on such an account; the fact that a substantial group of verbs have an echo vowel at the end of their bound stem would be a simple coincidence. Indeed, there is considerable evidence supporting the psychological reality of synchronic rule application in irregular morphophonological classes in other languages, see, inter alia, Yang, 2002, Stockall and Marantz 2006. We assume that these Hiaki classes should be analyzed similarly to rule-based morphological classes in more well-studied languages. ${ }^{4}$

The second problem arises from the fact, alluded to but not exemplified above, that the bound vs. free alternation is a property of nouns as well as verbs in Hiaki, and that similar

\footnotetext{
$4 \quad$ However, see Bermúdez-Ortero 2013 for a thorough discussion and defense of stem-listing approaches to class properties in the grammar of Spanish; lexical redundancy correspondences over stored forms are argued to account for the systematicity of class-based effects in such a model.
} 
morphophonological processes derive bound nominal stems; bound nominal stems seem to fall into the same general classes that bound verbal stems do. Hiaki does not have as much robust derivational morphology for nouns as it does for verbs, but nouns can undergo incorporation or compounding productively, and when they do, they occur in their bound form. Consider the examples below.

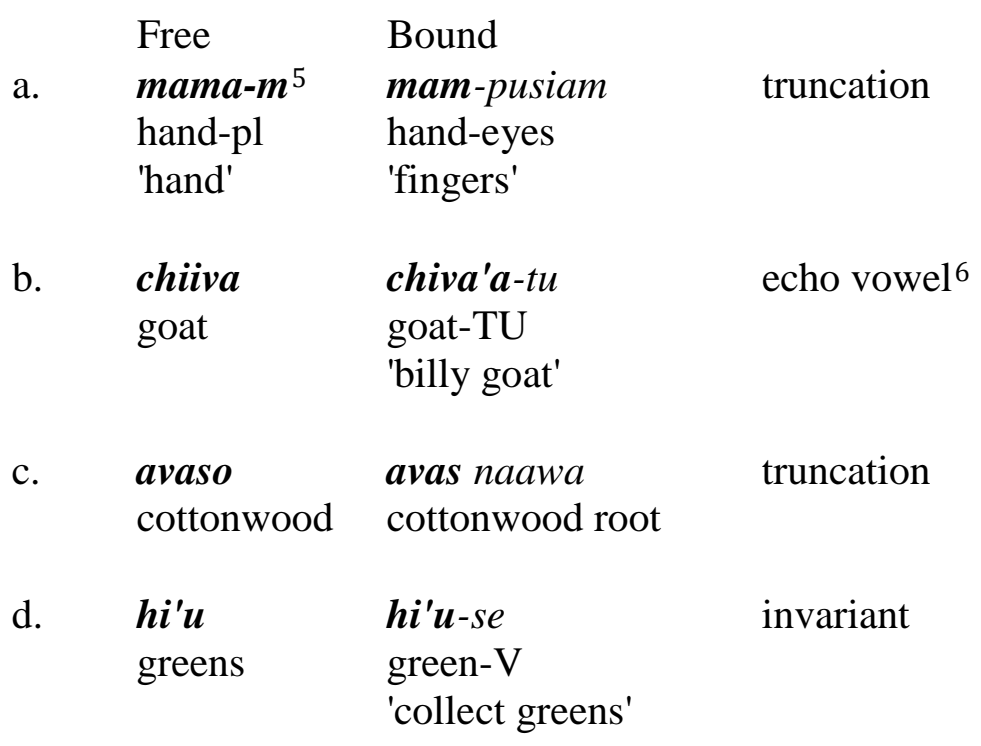

These patterns are robustly attested across the nominal vocabulary as well as in verbs.

That is, all roots, not just verbal roots, have bound and free stem forms. The problem this creates for a 'listing' approach is that the contexts which condition the appearance of each form are difficult to state in a unified way, although descriptively, the contexts are clearly unified: Inflectional morphology, whether verbal or nominal, attaches to free forms; derivational

$5 \quad$ Note that mamam, 'hand', is mandatorily plural when free in the language; it is a member of a substantial class of such pluralia tantum nouns in Hiaki, analogous to scissors or pants in English. It is nonetheless clear that the free stem form is mama-, not mam-; when the plural suffix - $m$ is added to a consonant-final stem, the epenthetic vowel which repairs the coda cluster violation is -i-, not - $a$ - (consider tekil, 'job', tekilim, 'jobs').

$6 \quad$ Recall that vowel shortening, as in the first syllable of chiiva chiva'a- here, is a regular phonological process in the language that occurs regardless of whether the affixation that triggers it is inflectional or derivational; hence we do not include 'vowel shortening' in our description of the process that forms the bound stem here, since we cannot distinguish the regular vowel shortening process triggered by affixation from vowel shortening for stemformation. 
morphology attaches to bound forms. These aren't the typical kinds of conditioning environments for insertion rules, however. The rule above referred to $\mathrm{Asp}^{0}$ as the conditioning context for the appearance of the free form, but this is obviously inadequate to characterize the nominal stem alternations in (5), which don't appear in a verbal extended projection. In order to unify the conditions for the insertion of the free form across nominal and verbal environments, a diacritic, perhaps something like [+inflectional], would be required, since it would be different inflectional categories, $\mathrm{Asp}^{0}$ in the case of verbs and probably $\mathrm{Num}^{0}$ in the case of nouns (cf. 5a), which trigger the insertion of the free form.

Further, and more theory-internally, there is a problem of locality in stating the conditioning environment. In DM, the fundamental lexical terminal nodes are acategorial, provided with their nominal or verbal character by merger with an $n^{0}$ or $v^{0}$ head, which, on a 'listing' approach, intervenes between the $\sqrt{ }$ element being inserted and the supposedly conditioning inflectional category. (The acategorial character of roots is supported by the fact that nouns and verbs are parallel in having distinct stem forms with similar formation patterns.) The theory doesn't make available any obvious notation that will ensure that just a single $\mathrm{x}^{0}$ category intervenes between a terminal node and the inflectional category which licenses the insertion of the free stem. A rule like that in (4) demanding adjacency between a $\sqrt{ }$ and some head with a [+inflect] diacritic is unworkable even for underived nouns or verbs, since the $v^{0}$ or $\mathrm{n}^{0}$ intervenes between the $\sqrt{ }$ and the [+inflect] head above, so the free forms would never meet the licensing criterion. Both simple nouns and verbs and those that undergo further derivation require an $x^{0}$ to be adjacent to the $\sqrt{ }$, and so the contexts for $\sqrt{ }$ spell-out are not differentiated 
locally. ${ }^{7}$ A stem-insertion rule would have to make reference to a complex hierarchical context like $\left[\left[\ldots \mathrm{x}^{0}\right] \mathrm{X}_{[+ \text {infl] }}^{0}\right]$ in order to even get the facts descriptively correct. ${ }^{8}$

To recap: The first problem for a listing approach is the fact that there are groups of lexical items whose free and bound forms appear to be related by particular phonological processes. Positing stem classes is motivated by such groups of forms, but the listing approach does not reflect such groupings. The second problem is the difficulty of stating the correct morphosyntactic conditioning environment for insertion of particular listed items, which crosscuts lexical categories: insertion of the free form would have to be triggered by diacritics such as [+inflect] occurring in a specific but non-local configuration with respect to the conditioned root. Given that the notion of 'stem-formation class' is appropriate in the characterization of the Hiaki data, and that a listing approach fails to capture this notion, what would a more successful proposal look like? We turn to this question in the next section.

\section{The conditioning of stem-forming Readjustment rules in Hiaki}

Having dismissed the 'listed stem' approach, we next consider an alternative more consonant with the conclusions of Embick and Halle (2005), according to which the free/bound stem alternations are derived via morphophonological readjustment rules conditioned by classes, a.k.a. lists of roots (which, in the case of wholly irregular stem-forming rules, may just contain a single

\footnotetext{
$7 \quad$ The question of conditioning across intervening morphology is of course highly pertinent in other frameworks as well, see, for example, Carstairs (1987) and subsequent work. Since in simple nouns and verbs the intervening morphology at issue here is null, however, the locality of the context under discussion is an issue mostly for theories which make robust use of zero morphs, as Distributed Morphology. See Embick 2010 for an in-depth discussion of these issues.

$8 \quad$ However, see Bobaljik and Wurmbrand (this volume) for a possible mechanism for suppressing the implementation of cyclic spell-out which relates cyclic behavior to the selectional relationship between the cyclic head and its immediately c-commanding head. It remains to be seen whether such a mechanism could be relevant to the derivation of the Hiaki forms under discussion here.
} 
item). We briefly sketch how the problem of stating the correct environment for the application of such readjustment rules evaporates when we consider where the morphosyntactic cycle, a.k.a. phase boundary, is located within the Hiaki word. We then turn to our primary concern, which arises from the interaction of suppletion with Hiaki stem alternations. We argue that the fact that distinct suppletive realizations of the same root can belong to different form classes shows that the stem-class feature of Hiaki words are a property of Vocabulary Items, not a property of the underlying abstract roots.

\subsection{Readjustment rules for Hiaki stem forms}

Readjustment rules apply to intermediate phonological representations during the derivation from syntactic structure to phonological form, following Vocabulary Insertion but prior to and consequently possibly bleeding the application of the regular phonological processes. The sequence of operations that may occur following Spell-Out, in the morphological component that maps syntactic representations to phonological objects for interpretation by the sensory-motor system is illustrated in (6):

(6) Operations that may apply to a syntactic representation at Spell-Out

Lowering
Linearization $\rightarrow \begin{aligned} & \text { Dissociated } \\ & \text { morphemes } \\ & \text { inserted }\end{aligned} \rightarrow \begin{aligned} & \text { Fission } \\ & \text { Fusion }\end{aligned} \rightarrow \begin{aligned} & \text { Vocabulary } \\ & \text { insertion }\end{aligned} \rightarrow \begin{aligned} & \text { Readjustment } \\ & \text { rules }\end{aligned} \rightarrow \begin{aligned} & \text { Phonological } \\ & \text { rules }\end{aligned}$

If Hiaki bound stem forms are the result of applying readjustment rules to free forms, they would involve phonological processes like prosodically-driven truncation (Class 1), affixation of CV syllable whose segmental content is determined by (e.g.) left-to-right spreading 
(the echo vowel, Class 2), raising of a final mid front vowel (Subclass i) ${ }^{9}$, etc. It is slightly more problematic to derive the free forms from the bound forms, mainly because the final material of the free forms appears to be more idiosyncratic than the final material of the bound forms, which often seems to be generated by copying the preceding vowel. So, for example, in Subclasses ivvii, listed in table 2 above, the bound form always involves two copies of the penultimate vowel of the free form, but the ultimate vowel of the free form can be either - $a$ or $-e$, apparently an idiosyncratic property of the stem. ${ }^{10}$ Similarly, in Class 1 (the 'truncation' class) the bound forms lack material that is idiosyncratic to the free stem, not independently predictable in any way, so, e.g. there are truncated stems whose free form contains a final $-a$ and the truncation consists in omitting that -a (poona pon- 'play (instrument)', bwiika bwik- 'sing', miika mik- 'give') but other members of the class involve omitting a final -e (bwase bwas- 'cook', chupe chup- 'finish', koche kot- 'sleep') or -o (avaso avas- 'cottonwood'). A few involve omission of a final CV syllable: (hapte hap- 'stop') or two final vowels (yosia yoh-, 'sleep').

Given that the bound forms seem to be more regular and in some cases to have lost information present in the free form, we will take the free form to be basic and assume that the readjustment rules derive the bound form from the free form. We will not attempt to formalize each of the readjustment rules here, but merely insert descriptive names for them which

$9 \quad$ Ora Matushansky (p.c.) asks whether subclass (iii), involving free forms ending in - $u$ and bound forms ending in $-o e$, might be derived by a readjustment rule involving raising of the final $-e$ to $-i$, followed by assimilation of $-o$ to the height of $-i$ (producing $-u$ ) and subsequent deletion of $-i$ in the free form. Such an approach to this subclass may be motivated by the fact that final V-deletion seems to be in evidence in other corners of the grammar, e.g. in alternate lexicalizations of adverbials like ket kechia, 'still'. Nonetheless, final -ui VV sequences seem to be well-formed in the language, in words like kumui, 'ego's mother's older brother', so such deletion is not a general phonological process.

$10 \quad$ A large number of verbs in Hiaki have transitive forms that end in - $a$ (and whose bound forms are Class 3 , invariant) and intransitive ones that end in $-e$ (and whose bound forms are Subclass $i, e \rightarrow i$ ). The verbs in Table 2 , however, are not among these transitive/intransitive alternating pairs, and contain transitives whose free forms end in -e (e.g. bwa'e, 'eat.tr') and intransitives whose free forms end in -a (e.g. hovoa, 'get full'). 
summarize their general effect. ${ }^{11} \mathrm{~A}$ few generalizations of note can be made; however obviously much work remains to be done to flesh out the analytical sketch presented here.

First, class membership cannot be fully predicted based on the phonological properties of the free form. Near minimal pairs exist, for example nooka, 'talk, speak to' is a member of the truncating Class 1 (bound stem nok-), but yooka, 'paint' is a member of the echo vowel Class 2 (bound stem yoka'a-). Similarly, naate, 'begin, start' is a member of the invariant Class 3, but waate, 'remember' is a member of the $e \rightarrow i$ Subclass (i).

Second, the bound form of a Truncation class word is always a heavy syllable, usually $\mathrm{C}(\mathrm{C}) \mathrm{VC}$ (as in nok-, 'talk'). This leads to a conjecture regarding the derivation of the forms of subclasses (iv)-(vii) in Table 3. It could be that two separate processes apply to generate this apparent pattern of vowel-matching: Truncation (as in Class 1), followed by Echo Vowel (as in Class 2), with the latter possibly motivated by a preference for a bimoraic foot at the end of a bound stem. ${ }^{12}$ This sequence would generate the bound form of, e.g., bwa'e as follows:

$$
b w a^{\prime} e+\text { Truncation } \rightarrow b w a \rightarrow b w a+\text { Echo Vowel } \rightarrow b w a^{\prime} a-
$$

\footnotetext{
11 Indeed, we remain agnostic concerning the character of the phonological component which interprets the output of the morphological component. It might well be, as proposed in Haugen (2008), an optimality-theoretic constraint system. In that case, readjustment rules could be analyzed as sub-phonologies or co-phonologies constrained to apply to small subsets of the lexicon. We leave this possibility for future research.

12 A bimoraic requirement on the foot on the right edge of a bound stem would provide a prosodic characterization of the motivation for truncation, as well, since the result of truncation seems always to be a heavy syllable.
} 
Such a derivation, if motivated, would provide additional support for the readjustment-rule approach, since an individual lexical item could be on the lists for two (or more) of the readjustment rules (which would have to be ordered with respect to each other). ${ }^{13}$

\subsection{The domain of stem-forming readjustment rules}

How can we characterize the environment in which such readjustment rules would apply? A key observation involves a close examination of the class of suffixes which require bound stems to attach to, given in (2a) above. Considered in terms of the hierarchical functional projections, the bound-stem requirement appears to end with affixes which occur in VoiceP. An overall templatic sketch of the left-to-right organization of the Hiaki verb complex is given below:

Schema of Hiaki verb structure:

Everything except the second instance of $\mathrm{V}$ is optional

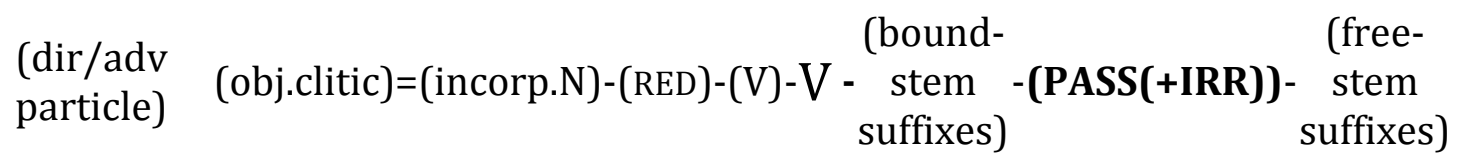

Passive and future/irrealis markers are a rigid boundary between bound-stem affixes and freestem affixes—-between derivation and inflection. They themselves take bound stems. The irrealis suffix -ne, although not obviously Voice-related, actually encodes both irrealis and active Voice. It is in complementary distribution with the realis passive -wa; one cannot add irrealis -ne to a

13 As noted by Matushansky (p.c.), the possibility that certain forms may be the product of the application of two independently active readjustment rules is in itself an argument for the existence of readjustment rules, and a strike against the listedness hypothesis, in which such interactions could not be captured. Alternatively, one might consider the notion that readjustment rules should be treated as cophonologies involving a few reranked constraints, restricted to a small list of individual lexical items, within an interpretive OT approach to the output of the DM morphological component. In that case, the apparent 'dual' application of readjustment rules in the case of forms like $b w a$ 'e $b w a$ ' $a$ would involve the optimal satisfaction of two lexically-restricted cophonologies (see footnote 11 above). We leave the investigation of such a possibility for future work. 
passive -wa (or vice versa) to mark as passive as irrealis. Irrealis passives employ a special portmanteau suffix -na in this position, expressing both properties at once. We speculate that Hiaki requires fusion of Voice and an immediately c-commanding Mood head. The key thing is that each clause can contain only one element which encodes Voice status, and that element must occur at the boundary between bound-stem selecting and free-stem-selecting material.

This distribution is extremely suggestive from the perspective of modern syntactic theory. Chomsky $(1995,2001)$ suggested that the derivation be passed on to Spell-Out in regular cycles, at specific boundary nodes, or phases. The external-argument-introducing node, which he termed $\mathrm{V}^{*}$, but which could equally be termed Voice, is one such phase. The fact that bound forms are required inside the passive implies that the stem-forming readjustment rules apply phaseinternally. Any element which is not left-adjacent to a phase edge is subject to the stem-forming readjustment rules. See Harley and Tubino Blanco (2012) for a more in-depth discussion of the syntactic character of this domain. ${ }^{14}$

It is worth noting that this view of the conditioning context entails that there are phase edges inside the nominal projection as well, which has become a relatively common position since the first introduction of phases (see discussion in, e.g. de Belder 2011, Kharytonava 2011). Nominal compounding and derivation takes place within that phase boundary and require bound nominal stems to appear everywhere except in final position; affixes in the higher inflectional

$14 \quad$ Note that a suppletion analysis of stem form alternations could equally appeal to this context, i.e. a rule stating that a bound stem form is inserted whenever a root node is not left-adjacent to a phase edge, or, conversely, that a free form is inserted whenever a root node is left-adjacent to a phase edge, assuming that both syntactic structure and linear order are accessible to the vocabulary insertion operation (rather than assuming, for example, that linear order is determined by the outcome of vocabulary insertion, as assumed in, e.g. Harley 2010). This weakens, somewhat, the locality-based objection to the 'listed' approach to stem-form alternations, but does not affect the other arguments presented above. Thanks to a reviewer for this observation. 
projections of $\mathrm{N}$ (NumP, CaseP) are outside this phase boundary and hence attach to free nominal stems.

\subsection{Class membership is a property of Vocabulary Items, not Roots}

Embick and Halle (2005) assume that the List 1 Root formatives are specified with phonetic feature information — that is, that Roots are not subject to late insertion from the Vocabulary (List 2), unlike functional morphemes. Their characterization of the content of Root elements is quoted below:

Roots: These make up the open-class vocabulary. They include items such as $\sqrt{ }$ CAT, $\sqrt{ }$ OX,

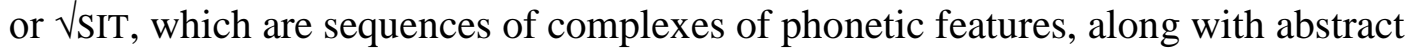
indices (to distinguish homophones) and other diacritics (e.g. class features) (Embick and Halle 2005:38)

Harley (2011) argues that Root nodes cannot contain phonetic features, but instead are subject to late insertion from List 2, the Vocabulary, just as abstract f-morphemes are. The argument is based on the claim that Roots have suppletive realizations that can compete for exponence, a claim supported by evidence from Hiaki and other Uto-Aztecan languages, as well as from other languages around the world, which have small but robust groups of suppletive forms that seem unlikely to be characterizable as 'light' verbs. (This conclusion is also supported by evidence from other languages described in Bonet and Harbour forthcoming.) She concludes that List 1 Root elements are individuated solely by their indices.

Setting aside that particular issue here, we will focus on whether class features are diacritics on elements of List 1 or List 2. The interaction of suppletion and class features in Hiaki indicates that stem class membership is a property of List 2 elements, not a diacritic on List 1 
elements, as proposed by Embick and Halle. As we will see below, this conclusion follows from the fact that suppletive variants of a single List 1 element can belong to different stem classes.

Hiaki suppletive verbs are conditioned by subject number (if intransitive), and object number (if transitive). The subjects of such verbs are argued by Harley et al. 2009 to be internal arguments; if so, conditioning of the relevant form is dependent on the number of the verb's internal argument. A representative sample is presented below:

(9) Hiaki suppletive verbs

$\begin{array}{lllll}\text { a. } & \text { vuite } & \text { run.sg } & \text { tenne } & \text { run.pl } \\ \text { b. } & \text { siime } & \text { go.sg } & \text { saka } & \text { go.pl } \\ \text { c. } & \text { weama } & \text { wander.sg } & \text { rehte } & \text { wander.pl } \\ \text { d. } & \text { kivacha } & \text { bring.sgObj } & \text { kiima } & \text { bring.plObj } \\ \text { e. } & \text { vo'ote } & \text { lie.sg } & \text { to'ote } & \text { lie.pl } \\ \text { f. } & \text { weye } & \text { walk.sg } & \text { kaate } & \text { walk.pl } \\ \text { g. } & \text { mea } & \text { kill.sgObj } & \text { sua } & \text { kill.plObj }\end{array}$

The above represents a selection from a set of about 14-15 total suppletive verbs in the language; the particular set varies somewhat between speakers and across dialects, but the seven listed above are among those which are consistent. It should be clear that it is implausible to treat these alternations in any other way than by listing. As in the case of the go/went alternation in English, the two forms compete with each other for realization, the winner determined by the number of the internal argument. A sample of such a rule is illustrated in (10). On the left is the abstract node from List 1, identified by its English translation ${ }^{15}$; on the right are the two Vocabulary Items which are competing to realize it.

15 Although the representation here suggests that these nodes are disambiguated by their meaning, in fact we assume they are individuated only by a contentless index, following Harley 2011. The index is interpreted by the equivalent of Vocabulary Insertion at LF-a kind of meaning-lookup procedure. 
Vocabulary Insertion rule for a Hiaki suppletive verb:

$$
\begin{aligned}
\mathrm{RUN} & \left.\rightarrow \text { /vuite/ / [[DP }+ \text { sg }] \_\sqrt{ }\right]^{16} \\
& \rightarrow \text { /tenne/ elsewhere }
\end{aligned}
$$

If stem class were a property of the abstract node of List 1 , then one would expect that the stem forms of both suppletive variants should belong to the same class and be subject to the same readjustment rules. Although this is the case for some of these suppletive pairs, it is not the case for others. Consider the following table:

\begin{tabular}{|c|c|c|c|c|}
\hline & \# & Free form & $\begin{array}{l}\text { Bound } \\
\text { form }\end{array}$ & Stem class \\
\hline RUN & $\begin{array}{l}\mathrm{sg} \\
\mathrm{pl}\end{array}$ & $\begin{array}{l}\text { vuite } \\
\text { tenne }\end{array}$ & $\begin{array}{l}\text { vuiti- } \\
\text { tenni- }\end{array}$ & $\begin{array}{l}e \rightarrow i \\
e \rightarrow i\end{array}$ \\
\hline GO (pres) & $\begin{array}{l}\mathrm{sg} \\
\mathrm{pl}\end{array}$ & $\begin{array}{l}\text { siime } \\
\text { saka }\end{array}$ & $\begin{array}{l}\text { sim- } \\
\text { saka'a }\end{array}$ & $\begin{array}{l}\text { Truncate } \\
\text { Echo Vowel }\end{array}$ \\
\hline WANDER & $\begin{array}{l}\mathrm{sg} \\
\mathrm{pl}\end{array}$ & $\begin{array}{l}\text { weama } \\
\text { rehte }\end{array}$ & $\begin{array}{l}\text { wee- } \\
\text { rehti- }\end{array}$ & $\begin{array}{l}\text { Truncate/EV } \\
e \rightarrow i\end{array}$ \\
\hline BRING & $\begin{array}{l}\mathrm{sg} \\
\mathrm{pl}\end{array}$ & $\begin{array}{l}\text { kivacha } \\
\text { kiima }\end{array}$ & $\begin{array}{l}\text { kivacha- } \\
\text { kima'a- }\end{array}$ & $\begin{array}{l}\text { Invariant } \\
\text { Echo Vowel }\end{array}$ \\
\hline LIE & $\begin{array}{l}\mathrm{sg} \\
\mathrm{pl}\end{array}$ & $\begin{array}{l}\text { vo'ote } \\
\text { to'ote }\end{array}$ & $\begin{array}{l}\text { vo'ote- } \\
\text { to'ote- }\end{array}$ & $\begin{array}{l}\text { Invariant } \\
\text { Invariant }\end{array}$ \\
\hline WALK & $\begin{array}{l}\mathrm{sg} \\
\mathrm{pl}\end{array}$ & $\begin{array}{l}\text { weye } \\
\text { kaate }\end{array}$ & $\begin{array}{l}\text { wee- } \\
\text { kat- }\end{array}$ & $\begin{array}{l}\text { Truncate/EV } \\
\text { Truncate }\end{array}$ \\
\hline KILL & $\begin{array}{l}\mathrm{sg} \\
\mathrm{pl}\end{array}$ & $\begin{array}{l}\text { mea } \\
\text { sua }\end{array}$ & $\begin{array}{l}\text { me'e- } \\
\text { sua- }\end{array}$ & $\begin{array}{l}\text { Truncate/EV } \\
\text { Invariant }\end{array}$ \\
\hline
\end{tabular}

Table 4: Stem classes of Hiaki suppletive verb alternants

$16 \quad$ Note that the singular form is the marked variant in Hiaki; in impersonal constructions, where number is unspecified, the plural form surfaces. Also note that the conditioning environment in (10) represents a syntactic structure, not a purely linear structure; it conveys the notion that the singular form of a root is inserted when that root is sister to a singular DP-i.e. when that root takes a singular internal argument. As noted above, Harley, Tubino Blanco and Haugen (2009) argue that all intransitive suppletive verbs in Hiaki are unaccusative. Other material may come to linearly intervene between the root and its base-generated sister DP, e.g. by virtue of DP movement to subject position, or the prefixation of an adverbial particle to the verbal complex, but since this vocabulary-insertion rule is sensitive to syntactic context not (necessarily) morphological adjacency, and since the rule presumably applies on the first Spell-Out cycle, prior to (e.g.) DP movement, such intervening material will not block insertion of the conditioned verb form. 
From the data in table 4 it should be clear, then, that suppletive variants of the same verb can have different stem class properties. Therefore, stem classes are a property of the vocabulary item, not of the abstract morpheme.

Note that the bound forms in table 4 support the point made earlier, that bound forms are always related phonologically to the free forms. The bound form of a suppletive variant of a verb is never itself another suppletive variant; rather, it is a form which relates to the free form according to some reasonable phonological transformation.

The stem form classes of Hiaki, then, are defined by the lists of roots that the contextrestricted phonological readjustment rules apply to. The lists themselves are references to the phonological content of a Vocabulary Item from List 2, not to the abstract content of a List 1 item. ${ }^{17}$

\section{Conclusions}

The Hiaki stem form classes, then, support three important conclusions about the architecture of the mapping to phonological structure. First, readjustment rules (or their equivalent) are a necessary feature of any morphological theory that wishes to characterize the patterns of stem formation of Hiaki: They are clearly phonological (even prosodic) in character, and yet are constrained to apply only to idiosyncratically restricted lists of lexical items. Second, the domain of application of these rules lines up quite well with the Minimalist construct of

$17 \quad$ A reviewer notes that one might consider whether the singular and plural forms of these suppletive verbs should not simply be considered independent verbs (i.e. independent List 1 elements), as proposed by Mithun 1988. In such an approach, each 'suppletive' pair is made up of two independent verbs which have effectively the same Encyclopedic content but one of which subcategorizes for singular arguments, the other for plural ones. If that were the case, the class features could be attached to the abstract verb rather than to the phonological exponent. The Hiaki cases, all of which involve verbs which subcategorize for an internal argument, do not provide the basis for a decisive argument against this position, but such an analysis would face the (in our opinion) significant drawback of failing to capture grammatically the intuition of Hiaki speakers that the singular and plural forms of these elements are 'the same verb', i.e. that they form part of a paradigm. See Bonet and Harbour (forthcoming) for a more decisive reply to Mithun's proposal based on the behavior of suppletive nominal roots, lacking a selected complement. 
phase, supporting the notion that the derivation proceeds cyclically, phase by phase. Finally, syntactically inactive class memberships of the kind observed in Hiaki stem forms are defined over Vocabulary Items, not over abstract List 1 morphemes. Indeed, it seems reasonable to think that class membership is not a diacritic on a Vocabulary Item, but instead is just a reflection of the presence of that vocabulary item on a particular readjustment rule's list of triggers. This opens the door to the possibility that certain apparently 'irregular' stem formations simply reflect the presence of a single root on the lists of two or more readjustment rules. The application of both rules, rather than either one or the other, can produce relatively uncommon bound form free form relationships. One case discussed above that might admit of such an analysis is $b w a$ 'e, 'eat', whose bound form, $b w a^{\prime} a-$, could result from the interaction of Truncation and Echo Vowel; it remains to be seen, however, whether such an analysis is viable for most or all the 'irregular' bound-stem types. We leave such investigation for future work.

\section{References}

Anderson, Stephen. 1992. A-morphous Morphology. Cambridge: Cambridge University Press. Aronoff, Mark. 1994. Morphology by Itself: Stems and Inflectional Classes. Cambridge, Massachusetts: MIT Press.

Bermúdez-Otero, Ricardo. Forthcoming 2013. The Spanish lexicon stores stems with theme vowels, not roots with inflectional class features. Probus 25.1.

Bobaljik, Jonathan, \& Wurmbrand, Susie. (this volume).

Bonet, Eulàlia and Daniel Harbour. Forthcoming. Contextual allomorphy. In Jochen Trommer (ed.), The Morphology and Phonology of Exponence. Oxford: OUP. 
Carstairs, Andrew. 1987. Allomorphy in Inflection. Croom Helm Linguistics Series, London: Croom Helm.

Chomksy, Noam. 1995. The Minimalist Program. Cambridge: The MIT Press.

Chomsky, Noam. 2001. "Derivation by Phase." In Michael Kenstowicz (ed.) Ken Hale: A Life in Language. MIT Press. Pages 1-52.

De Belder, Marijke. 2011. Roots and affixes: Eliminating lexical categories from syntax. Utrecht: LOT.

Embick, D. \& M. Halle. 2005. “On the Status of Stems in Morphological Theory”. In T. Geerts and H. Jacobs (eds), Proceedings of Going Romance 2003, Amsterdam: John Benjamins.

Embick, D. 2010. Localism versus Globalism in Morphology and Phonology. Cambridge: MIT Press.

Halle, M. and Marantz, A. 1993. Distributed Morphology and the pieces of inflection. In Hale, K. and Keyser, S. J., editors, The View from Building 20, pages 111-176. Cambridge MA: MIT Press.

Harley, H. (2010). "Affixation and the Mirror Principle." In Interfaces in Linguistics, ed. by Raffaella Folli and Christiane Ullbricht, 166-186. Oxford: OUP

Harley, Heidi. 2011. "On the Identity of Roots." Paper presented at the Approaches to the Lexicon workshop (Roots III), June 13, 2011, Hebrew University of Jerusalem, Israel.

Harley, H. and Rolf Noyer. 2000. Licensing in the non-lexicalist lexicon. In Bert Peeters, ed., The Lexicon/Encyclopaedia Interface, 349-374, Amsterdam:Elsevier Press. 
Harley, H., M. Tubino Blanco and J. Haugen. 2009. "Applicative constructions and suppletive verbs in Hiaki (Yaqui)." In L. Lanz, A Franklin, J Hoecker, E Gentry Brunner, M Morrison, and C Pace, editors, Rice Working Papers in Linguistics Volume 1, pp. 42-51

Harley, Heidi and Tubino Blanco, Mercedes, 2010. "Dos tipos de base verbal en Hiaki (yaqui)". In Análisi lingüístico: enfoques sincrónico, diacrónico e interdisciplinario, ed. by Rosa María Ortiz Ciscomani, p. 97-128. Editorial Unison, Hermosillo, Son., Mexico

Harley, Heidi and Tubino Blanco, Mercedes. 2012. Phase-theoretic mismatches in the morphology and syntax of Hiaki verb stems. Talk presented at Exploring the interfaces 1: Word Structure, held at McGill University, May 6-8, 2012.

Haugen, Jason. 2008. Morphology at the Interfaces: Reduplication and Noun Incorporation in Uto-Aztecan. Amsterdam: John Benjamins.

Kharytonava, Olga. 2011. Noms composées en turc et morpheme -(s)I. PhD. dissertation, University of Western Ontario.

Marantz, Alec. 1997. No escape from syntax: Don’t try morphological analysis in the privacy of your own lexicon. University of Pennsylvania working papers in linguistics, 4(2), pp. 201-225.

Mithun, Marianne. 1988. Lexical categories and the evolution of number marking. In Michael Hammond and Michael Noonan, eds., Theoretical Morphology: Approaches in Modern Linguistics, 211-234, San Diego: Academic Press, Inc

Siddiqi, Daniel. 2009. Syntax within the word: Economy, allomorphy and argument selection in Distributed Morphology. Amsterdam: John Benjamins. 
Stockall, Linnea and Alec Marantz. 2006. "A single route, full decomposition model of morphological complexity: MEG evidence". The Mental Lexicon, 7.1: 85-123.

Yang, Charles. 2002. Knowledge and learning in natural language. Oxford, New York: Oxford University Press. 